\title{
A Tribute to Professor Umberto Veronesi, 1925-2016
}

\section{Hommage au professeur Umberto Veronesi, 1925-2016}

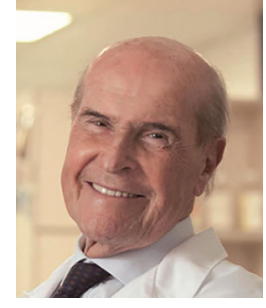

\section{A. Costa}

(C) Lavoisier SAS 2017

Professor Umberto Veronesi passed away peacefully at the age of 91 surrounded by his wife, seven children and many grandchildren, fading away with his unique and unforgettable smile at home in Milan.

He was an authentic master of science in that he used a pedagogic method based on the active participation of his collaborators towards the search of their own professional purpose and scientific interest. His greatest gift was his ability to get the best from his collaborators, promoting their careers based on merit. He instilled in many people his real passion for research. He was able to build warm and reassuring relationships with his collaborators, thanks to his elegant and charming way so that each of them was pressed to give their best.

The scientist Veronesi was a champion of breast cancer surgery; he was the first to demonstrate that conservative surgery with quadrantectomy was equivalent to radical mastectomy. He was also the first to use sentinel lymph node biopsy to avoid axillary dissection in clinically negative lymph node breast cancer. These procedures have changed the practice of breast cancer surgery worldwide and saved millions of women from the trauma of a mutilating surgery. Likewise, in the clinical field of prevention, Veronesi pioneered the concept of chemoprevention by assessing retinoid fenretinide and later tamoxifen to prevent breast cancer.

Veronesi, as a physician, operated on more than 30,000 women in his career. He was in the surgical theatre nearly every day and had an intense clinical practice until a couple of years ago. He was a reassuring doctor with a humane manner and most women were eager to be his patient. His surgical skill was outstanding and remains a reference also in terms of cosmetic results.

Veronesi, the manager, after having contributed to the founding of the National Cancer Institute (INT) in Milan, established the European Institute of Oncology: two internationally recognized centres of excellence for research in oncology. He was a great talent recruiter and he firmly believed in the equation "good research, better care".

He was founder and president of most of the European scientific societies (surgical oncology, mastology, the federation of cancer societies, FECS, now ECCO) as well as president of EORTC, UICC and many other organisations.

He founded the European School of Oncology in 1982, and dedicated a lot of time and energy to education and teaching. In 2003, he established the Umberto Veronesi Foundation, a charity aimed at funding academic research, which today is also an important vehicle for scientific knowledge and through Science for Peace, also a promotion of social solidarity for underserved populations.

Umberto Veronesi was a citizen of the world, but always proud of being Italian, serving his country as Minister of Health and as Senator. In 2000, he promoted the Italian law against smoking in public places, an initiative which aroused admiration and emulation in other European countries and will help to save many lives from the dangers of passive smoking.

Veronesi, the man of culture, promoted many great civil battles such as the biological testament and the right for a good death characterized by ideas and positions based on logical principles in the name of scientific thought. He was secular, but he had a deep knowledge of religions and their history. A nonconformist, he believed that prevention is the way forward in the current era of medicine dominated by economic interests and questionable cost-effective treatments.

His typical statement at the end of internal meetings was, "You should think bigger and conceive studies which represent a breakthrough for medicine". A lesson not easy to follow up.

\footnotetext{
A. Costa $(\bowtie)$

CEO of the European School of Oncology (ESO)

e-mail : acosta@eso.net
} 